\title{
Tracing resilience, social dynamics and behavioral change: a review of agent-based flood risk models
}

\author{
Alessandro Taberna ${ }^{1 *}$, Tatiana Filatova ${ }^{1,2 *}$, Debraj Roy ${ }^{1}$, Brayton Noll ${ }^{1}$ \\ ${ }^{1}$ Department of Governance and Technology for Sustainability (CSTM), University of Twente, Enschede, The \\ Netherlands \\ ${ }^{2}$ PERSWADE Research Center, School of Systems Management and Leadership, University of Technology Sydney, \\ NSW, Australia
}

\begin{abstract}
Climate change and rapid urbanization exacerbate flood risks worldwide. Recognizing the crucial role that human actors play in altering risks and resilience in flood-prone cities has triggered a paradigm shift in climate risk assessments. This shift drives the proliferation of computational models with explicit representation of societal dynamics and behavioral change, which increasingly simulate adaptation, learning, recovery and reorganization essential for tracing the evolution of resilience rather than only risks. Yet, replacing a single representative rational actor, dominant in climate policy models with various behaviorally-rich agents that interact, learn, and adapt, is not a straightforward feat. Focusing on the costliest climate hazard, flooding, we review computational agentbased models that include behavioral change and societal dynamics. We distinguish between two literature streams: one stemming from economics \& social sciences and the other from hydrology. Our findings show that most studies focus on households while representing other agents' (government, insurance, urban developers) decisions in the face of risks simplistically and entirely overlooking firms that are key to a resilient regional development. The two streams vary in the extent they ground the agents' design in social theories and behavioral data when modeling bounded rationality, a core component in computing adaptation and learning decisions. While both communities aspire to trace feedbacks that agents collectively instigate, they employ different learning mechanisms and interactions when computing societal dynamics in the face of climate risks. In both streams, the dynamics of hazard, exposure, and vulnerability components of flood risks driven by incremental adaptation of agents are well represented, in contrast to transformational adaptation. We highlight that applying a complex adaptive system perspective to trace the evolution of resilience can lead to a better understanding of societal adaptation to climate-driven risks. The methodological advances in computational models with heterogeneous behaviorally-rich adaptive agents are relevant for adaptation to different climate-driven hazards beyond flooding.
\end{abstract}

\section{Keywords}

Agent-based modeling; climate change; adaptation; urban; behavior; floods; resilience

Correspondence:
Contact A. Taberna at a.taberna@utwente.nl and T. Filatova at t.filatova@utwente.nl

Cite this article as:

Taberna, A., Filatova, T., Roy, D. \& Noll, B.

Tracing resilience, social dynamics and behavioral change: a review of agent-based flood risk models Socio-Environmental Systems Modelling, vol. 2, 17938, 2020, doi:10.18174/sesmo.2020a17938

This work is licensed under a Creative Commons Attribution-NonCommercial 4.0 International License. 


\section{Introduction}

Rapid urbanization and climate change exacerbate natural hazard risks worldwide. As the costliest climateinduced hazard, floods impose billions of property damage globally, disrupt millions of livelihoods, and take thousands of lives annually. Individuals and institutions have adapted to floods with varying degrees of success. Since the 1950's, top-down governmental and public planned climate change adaptation (CCA) - such as dikes strengthening, beach nourishments and zoning - has been the dominant societal response to flooding. Yet, coordinated anticipatory actions involving stakeholders across all social levels are required to address rising flood risks (Adger et al., 2005). CCA acknowledges adaptation by private actors as essential and complementary to public actions (Fankhauser et al., 1999; Mendelsohn, 2000). The increasing knowledge about 'behavioral climate change adaption' derives from the extensive use of surveys and other empirical studies that study factors triggering private adaptation for different people, behavioral biases, and the role of peer influence (Bamberg et al., 2017; Noll et al., 2020; Steg \& Vlek, 2009). It highlights the necessity to overcome the rational optimizing behavior used in traditional flood risk assessments and corresponding models by accommodating the complexity of behavioral heterogeneity and social interactions.

Moreover, the increasing uncertainty, frequency, and severity of natural hazards challenge the risk reduction paradigm in managing climate change impacts on human societies (Bayer et al., 2014; Wilson et al., 2020). Therefore, policymakers have increasingly embraced resilience thinking as a response to climate change (Field et al., 2017). Resilience in the view of complex adaptive systems (CAS) is defined as the ability to withstand a shock and cope, learn, adapt, and (self)-reorganize during a recovery to continue long-term development despite adversities (Folke, 2006; Mochizuki et al., 2018). It encompasses the traditional risk framework focused on coping and based on the evolution of expected damages, either through probability, exposure, and vulnerability adjustments. Yet, resilience goes further by considering the consequences to the socio-economic system in the long run, the distribution of risks across various actors, and how these factors contribute to their behavioral responses. Actors can learn and adapt by changing their behavior incrementally or drastically, possibly by collectively reorganizing entire social institutions, which leads to different pathways and speeds of recovery.

The recognition of the crucial role of human actors in altering these risks and resilience in hazard-prone cities calls for developing behaviorally-rich models that couple social and environmental dynamics in flood risk assessments (Aerts et al., 2018). Agent-based models (ABMs) are designed to study individual decisions and social institutions' dynamics in computational models, especially when these societal dynamics are to be coupled with the environment (Filatova et al., 2013). For flood risk assessments, ABMs are uniquely positioned to quantify the cumulative effects of actions of various stakeholders, considering the influence of behavioral biases, social interactions, and cross-scale feedbacks that may magnify existing flood risks. In the past years, the scientific community has witnessed a proliferation of ABMs applied to study various aspects of flood risks that explicitly simulate diverse boundedly-rational agents. Yet, replacing a representative rational actor dominant in climate policy models with various behaviorally-rich agents that interact, learn, and adapt is not a straightforward process (Stern, 2016).

This article presents a systematic review of the first generation of computational models that include behavioral change and social dynamics in flood risk assessments. We focus on peer-reviewed articles that study the midto long-term flood risk and resilience in urban areas in light of climate change. Hence, papers reporting simulations to explore evacuation and a short-term reconstruction (days and months after a hazard event, usually less than one year) are outside the scope. Our review centers around the CAS perspective (Martin-Breen \& Anderies, 2011; Wilson et al., 2020). At first, we take the three traditional components of risk - hazard, exposure and vulnerability - that predefine how well a socio-environmental system is able to cope with a shock. Furthermore, we advance the coping element of resilience to encompass adaptive behavior, learning, and longterm recovery and reorganization (Figure 1 ).

In this article, we demonstrate how our understanding of resilience can be advanced through the use of ABMs from different disciplines. From the CAS perspective, adapting and learning are the key elements shaping resilience (Folke, 2006). When discussing the learn-adapt cycle (Figure 1), we focus on how various stakeholders in CCA are represented in computational models, on the type of actions and interactions they pursue, and on how they learn when making decisions under risk and uncertainty. We examine social science theories and data that lay the foundation of such a learn-adapt cycle for boundedly-rational agents in flood risk ABMs. Furthermore, we deliberate on feedbacks between socio-economic and environmental systems and the capacity 


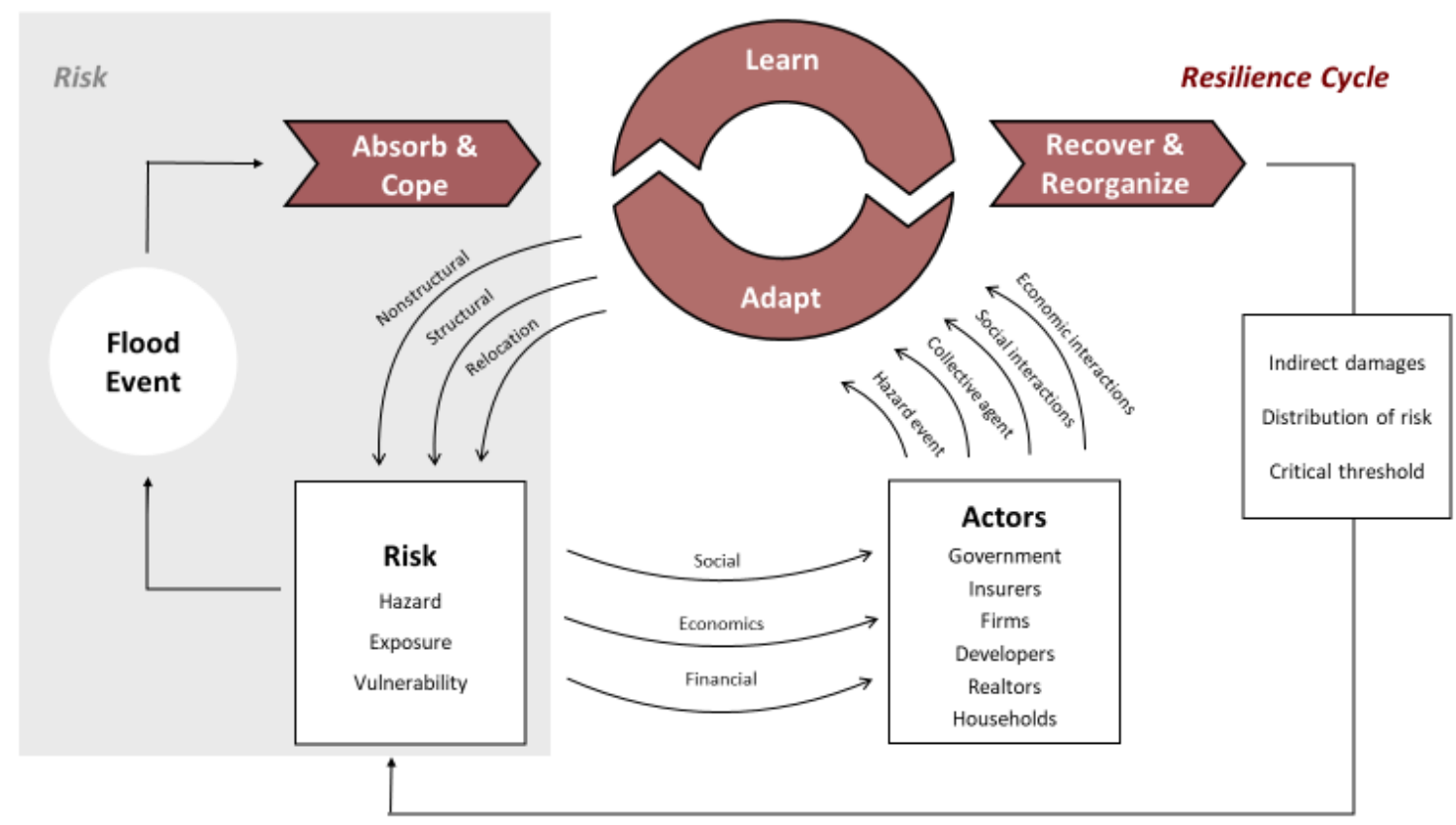

Figure 1: Capturing resilience in complex adaptive systems (CAS) and in CAS models.

of such CAS to recover and to reorganize (Figure 1). Flooding is a multi-faceted problem. It is, therefore, unsurprising that different disciplines adopt varying modelling approaches. Among behaviorally-rich computational models of social dynamics in the face of floods we distinguish between two strands of literature: one focusing mainly on relocations and exposure, which we call further Market \& Relocation, and another focusing on hazard and vulnerability modeling stemming from Socio-Hydrology. Our review covers both groups and discusses how their disciplinary views represent various elements of the CAS resilience framework (Figure 1) and its components -'cope', 'adapt', 'learn' and 'recover \& reorganize' -in agent-based flood models.

The article first describes our search strategy and the review criteria. We then explain how risk components, spatial and temporal scales have been modeled in the context of resilience. Next, we discuss the type of actors, theoretical and empirical micro-foundations of their decisions, feedback, and recovery; we highlight differences in disciplinary approaches that were evident. Further, we discuss how resilience-thinking can reconcile current efforts from social and environmental sides by learning from each other. Finally, we summarize gaps and challenges for future research, focusing on features that a new generation of CAS models integrating interdisciplinary research traditions in flood resilience assessments should encompass.

\section{Methods}

\subsection{Scope and search strategy}

We systematically review ABMs that explore mid-term (1 to 3 years after an event) and long-term (longer than three years) reactions of socio-economic systems threatened by flood hazards in urban areas (hereafter floodABMs). While floods impact societies on various fronts, including farmland and natural ecosystems, most of the damage and disruption occurs in urban areas, which serve as dense clusters of population and infrastructure (Jha et al., 2011). Rapid urbanization in flood-prone areas is a primary threat to pursue the Sustainable Development Goal 11. Hence, our review focuses on the socio-economic impacts of urban floods and responses, particularly the adaptation behavior of different actors and resilience against floods in the face of climate change.

We implemented an extensive search using the SCOPUS database to retrieve relevant flood-ABMs papers (Figure 2). Confined to papers written in English and published in peer-reviewed journals, our search returned 348 results (as of the 10th of May 2020). We then further refined the search by screening titles, abstracts, and eventually full-texts to filter out the articles that: 
- belong to fields outside our research domain (Veterinary, Astronomy, Microbiology);

- mention river or coast (often concerning the geographical location of a case-study) but did not present an ABM to study the socio-economic impacts of flooding. These articles often include ABMs that explore urban expansion (land-use), water-use and management, tourism, or non-human dynamics (biology, ecology, chemistry, archeology). Also, those ABMs that model responses to other natural hazards such as Tornado or Earthquake are excluded;

- model flooding unrelated to urban areas (farmers, villages, rural areas). Albeit similar, these papers look at CCA from a different perspective on natural hazards and human actions. The former includes mainly droughts, a primary concern among farmers. The latter follow crop growth models and their time scales, aiming to maximize harvest productivity despite adversities; or

- focus on the short-term operational response to floods (evacuation, emergency management, immediate recovery).

Using the above-mentioned criteria, we collected 28 articles published between 2009-2020 to form the core of our analysis ${ }^{1}$ (Figure 2). Some of the comprehensive papers that look at societal dynamics and floods are outside the scope because they prioritize different processes such as the immediate evacuation response (Dawson et al., 2011) or a short-term recovery in the first few months (Coates et al., 2019). Alternatively, some articles use cellular models (McNamara \& Werner, 2008; Werner \& McNamara, 2007) or are not peer-reviewed (Sobiech, 2013; Walsh \& Hallegatte, 2019).

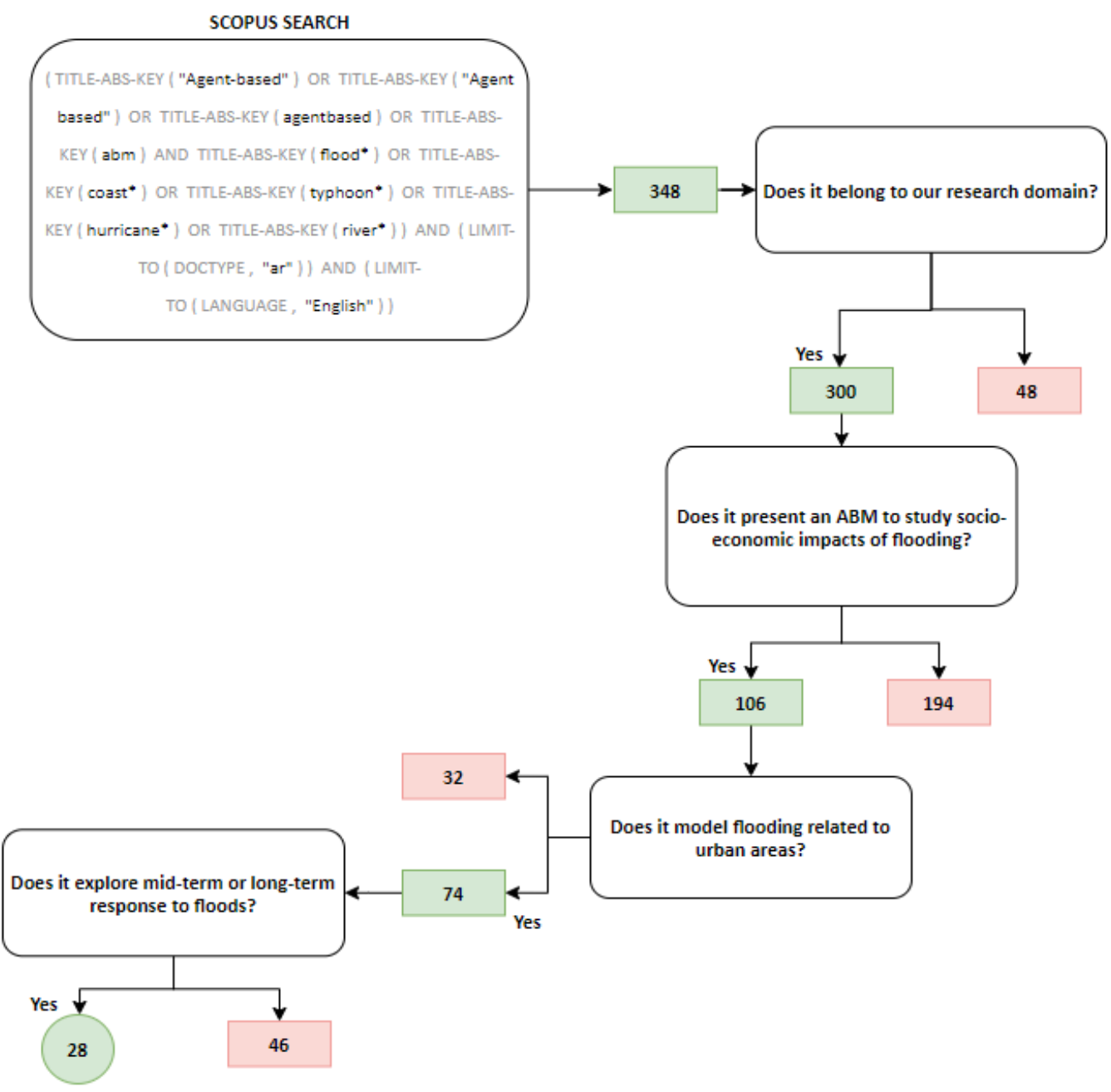

Figure 2: Search and filtering process to select articles for the review.

\footnotetext{
1 While an ABM developed by a team of authors constantly evolves adding new elements to address unique research questions in each article, the comparison of published versions of the same family of ABMs is hindered due to irregular reporting on code modifications. To assure the consistency and reproducibility of this review, we compare published articles rather than models.
} 


\subsection{Review criteria}

Several aspects, including flood resilience, ABMs, and contemporary modeling challenges, are relevant when considering CAS resilience. Hence, we rely on the recent review articles from these domains to develop the criteria and align them with the CAS resilience framework (Figure 1).

From the view of ABMs (Filatova et al., 2013; Groeneveld et al., 2017), clarity on empirical and theoretical foundations guiding agents' behavior and the presence of explicit feedbacks between human and environment systems are essential. They also form the basis of agents' adaptive behavior and learning that strengthen resilience. From the flood perspective, Aerts et al. (2018) argue for the importance of including dynamic vulnerability - human adaptive behavior and risk perception - into flood risk assessments, calling for modeling of different risk components (hazard, exposure, and vulnerability). Stressing the paradigm shift from risk to resilience, McClymont et al. (2019) stand with the proposition of Tempels and Hartmann (2014) that a coevolution between social and natural-physical systems across scales is a pathway to improve the resilience of complex adaptive socio-environmental systems. Concerning the latter, Elsawah et al. (2020) review grand challenges in socio-environmental systems modeling and stress that integrating the human dimension, including the behavior of different stakeholders, is a top priority. They note that caveats deal with scales, systemic changes (transformational vs. incremental CCA in case of floods), matching models with data, among other aspects.

Following the CAS resilience framework (Figure 1) and the challenges highlighted in the above relevant reviews, we define the following research questions, which serve as criteria for assessing the selected set of articles on flood-ABMs:

\section{Criterion 1. Coping with flood risk:}

1.1. How do the 3 risk components - hazard, exposure and vulnerability - enter an agent-based model? How do they link to socio-economic agents?

1.2. What spatial and temporal scales are appropriate to capture societal resilience to floods?

\section{Criterion 2. Learn-adapt cycle in flood-ABMs:}

2.1 Which actors are modeled? How do they interact?

2.2 Which actions drive agents' behavior? Do they evolve through learning?

2.3 What are the theoretical micro-foundations of these decisions? What socio-economic or behavioral data is employed?

\section{Criterion 3. Recovery and reorganization in flood-ABMs:}

3.1 How is the CAS capacity to recover and self-organize modeled?

This review does not focus on other relevant agent-based modeling aspects such as model transparency, uncertainty exploration, and validation, which are extensively discussed elsewhere (Kremmydas et al., 2018; O'Sullivan et al., 2016). An adequate overview of these criteria would require significant space and dilute this paper's focus, namely flood-ABMs within the CAS resilience framework.

\section{Results and discussion}

Articles that report $A B M$ analysis of mid- and long-term flood impacts on human societies share many commonalities. However, managing flood risks and building urban resilience is a complex topic; thus, different disciplines have approached the issue differently. We identify two broad categories of flood-ABMs:

(1) Those developed principally by environmental scientists and hydrologists, which traditionally focus on changes in hazard, vulnerability, and expected annual damage (EAD), hereafter Socio-Hydrology (SH) group;

(2) Those developed by economists and geographers focus on exposure, land use, and market dynamics that affect values at risk, hereafter Markets \& Relocation (MR) group.

The two strands of literature vary in the types of research questions, objectives, critical characteristics of agents and their decisions, and the model output. The flood-ABMs in the $\mathrm{SH}$ group usually analyze how flood risks and EAD change over time. Starting from 2013, the SH community has adopted the ABM method in the quantitative 
flood risk assessments driven by the ambition to include human behavior (McNamara \& Keeler, 2013) and to explore natural-human interactions quantitatively (Di Baldassarre et al., 2013; Sivapalan et al., 2012). The SH group advances flood risk modeling by tracing endogenous vulnerability changes, yet assuming exogenous or inexistent changes in people and assets at risk (exposure). The articles assigned to this group (65\% of our review) distinguish themselves in their output measures, focussing on quantifying changes in direct EAD, with just two articles reporting the diffusion of CCA actions (Erdlenbruch \& Bonté, 2018; Haer et al., 2016). The first flood$A B M$ in the $M R$ group dates back to 2009 , focusing on both direct and indirect flood impacts in urban areas, and the exposure component of risk. The MR flood-ABMs' output is different from the SH group and typically aims to trace the effects of flood risks on location choices, house prices, and overall changes in the urbanization patterns and economic value at stake (Filatova, 2015; Walls et al., 2018). Therefore, this group advances flood risk modeling by replacing the assumption of the static value of assets at risk with the endogenous housing market and relocation dynamics, usually grounded in urban economics. The $M R$ group also explicitly considers migration due to floods and focuses on the number of people at risk (Hassani-Mahmooei \& Parris, 2012).

There are examples of flood-ABMs that bridge the two groups by measuring both the endogenous changes in housing prices that shape values of assets at risk and estimating EAD with related vulnerability (Chandra-Putra et al., 2015; McNamara \& Keeler, 2013) ${ }^{2}$. Further, there are examples of $M R$ articles that link vulnerability elements, namely insurance uptake (Magliocca \& Walls, 2018) and insurance claims (Chandra-Putra \& Andrews, 2019) as a form of validation of agents' decision-making process. Such structural realism tests the ability of a model to replicate new patterns that were not explicitly included in its initial design (Grimm \& Berger, 2016; Latombe et al., 2011). Notably, all flood-ABMs model Household agents and use their spatial location to link natural and human subsystems, further reinforcing the connection between $S H$ and $M R$ groups.

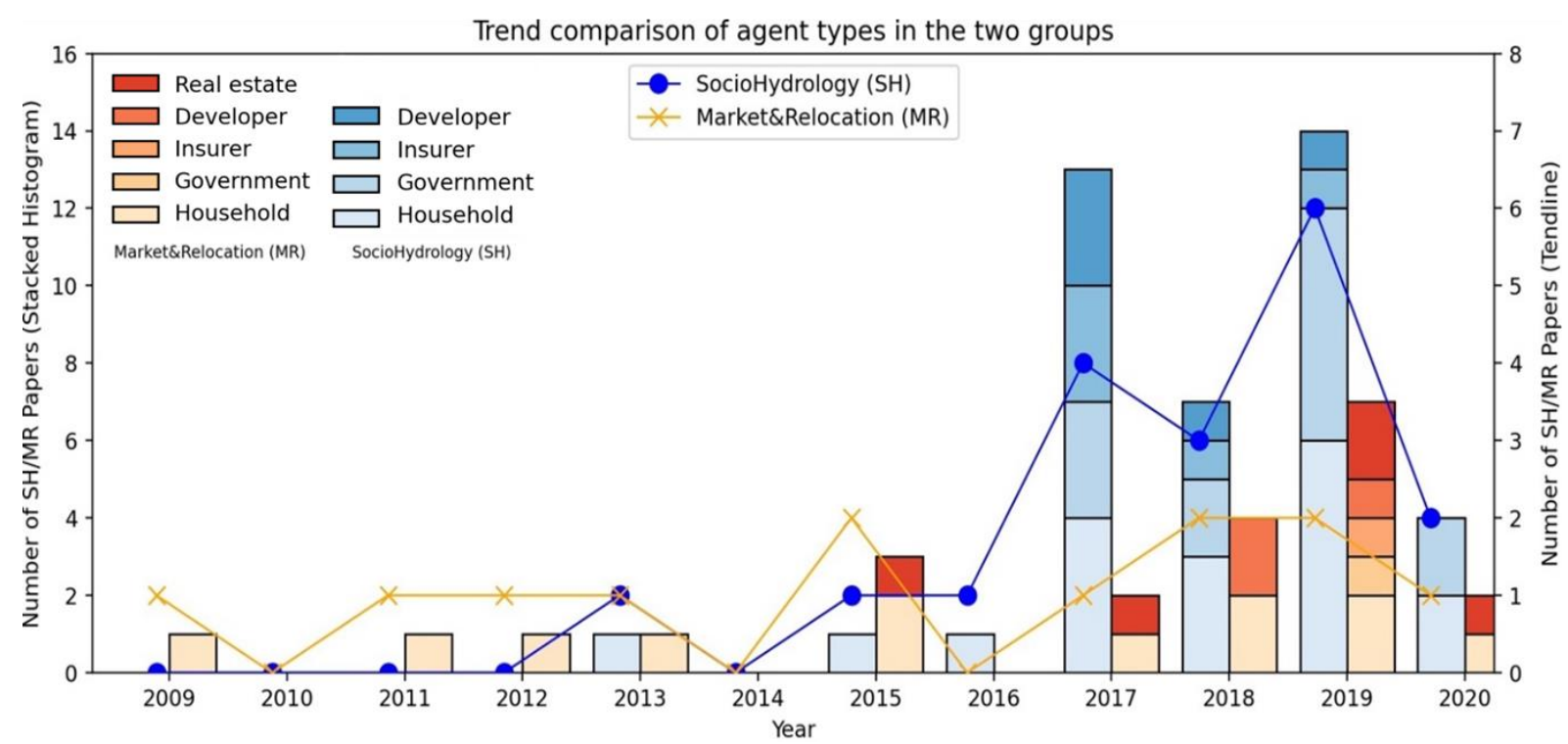

Figure 3: The trend in the number of published articles reporting flood-ABMs that originate from Socio-Hydrology (SH) versus those that focus on Markets \& Relocation (MR). The histogram illustrates the type of stakeholders being modeled within each group. Please note that the year 2020 includes only articles published before the 10th of May.

\subsection{Coping with flood risk}

\subsubsection{Risk components in Flood-ABMs}

Flood-ABMs actively model how natural factors and human actions shape the level of risk, defined as hazard * exposure * vulnerability (IPCC, 2014) over time. Thus, the ability of a socio-economic system to cope with flooding is well represented. Furthermore, we identify that the two groups mainly focus on risk components differently. The $S H$ group exploits more in detail the hazard and vulnerability components, while the $M R$ group centers on exposure (Table 2).

\footnotetext{
2 Therefore, we count these two articles as overarching and belonging to both groups.
} 
Hazard refers to the probability that the socio-economic system under study has to cope with a flood of a certain magnitude. In flood-ABMs, scholars use four alternatives to estimate such probability. The MR group often uses non-linear distant-dependent functions from the coast or river as a proxy of hazard probability (Filatova et al., 2011; Magliocca \& Walls, 2018; Walls et al., 2018). Second, flooding probabilities can be determined through statistical methods that sample historical values (Chandra-Putra et al., 2015; Han \& Peng, 2019; Tonn et al., 2019; Tonn \& Guikema, 2018). Alternatively, location-specific fixed flood maps (Dubbelboer et al., 2017; Haer et al., 2017) are used for different return periods, for example, 1:100 flood. Finally, there are examples of articles belonging to the $\mathrm{SH}$ group that employ hydrologic models (Abebe et al., 2019a, 2019b; Haer et al., 2019, 2020; Löwe et al., 2017; McNamara \& Keeler, 2013; Michaelis et al., 2020). Despite the increased complexity of coupling engineering and socio-economic models, hydrologic models' presence establishes a two-way feedback between human and natural systems. Specifically, human actions such as land-use affect overall surface imperviousness (Abebe et al. 2019a, 2019b) or rain drainage (Löwe et al., 2017). These changes are inputs in the hydrologic models that, in return, provide dynamic flood maps for a given return period. With a two-way linkage, hazard affects human actions, but social activities have consequences on future floods.

Moreover, flood probabilities might evolve with climate change and human actions. The latter entail governmental CCA actions - such as building dikes or performing sand nourishments (see 3.2.2) - that decrease such probabilities. The former, although we have not experienced it yet, it is an additional factor of risk included in flood-ABMs through various forms. In the most simplistic, it enters as repetitive floods to proxy increasing future frequency (de Koning \& Filatova, 2020). A more advanced way to include climate change into flood-ABMs is to use sea-level rise as an input of the aforementioned hazard sub-models (Han \& Peng, 2019; HassaniMahmooei \& Parris, 2012; Haer et al., 2017; McNamara \& Keeler, 2013). Finally, few flood-ABMs directly model increasing hazard probabilities (Magliocca \& Walls, 2018; Walls et al., 2018) or floodwater levels (Tonn et al., 2019) under different climate change scenarios, linking greenhouse gas emissions levels with changing severity and probability of floods (Dubbelboer et al., 2017; Haer et al., 2017, 2020).

Yet, almost half of the articles (15:28) treat the natural hazard component of risk as constant, based on empirical evidence. Only 4:12 of the MR group models dynamic climate conditions compared to 10:18 of the SH group. This may be related to the temporal horizon of a flood-ABM, typically shorter in the MR group (Table 1).

Vulnerability determines the amount of damages that a defined amount of people and assets suffers in case of a flood. The most common option within the $\mathrm{SH}$ group is to employ empirical water-depth damage functions, often for specific building (Dubbelboer et al., 2017; Haer et al., 2020; Han \& Peng, 2019). The MR ABMs treat vulnerability simplistically, for example, calculating damages as a fixed percent of property value averaged for the whole floodplain (de Koning et al., 2017, 2019). Moreover, in flood-ABMs, agents can decrease their vulnerability, undertaking structural CCA actions such as elevating a house or installing flood barriers, which is the focus in the $S H$ literature (17:18 papers) (see 3.2.2, Table 2).

Exposure indicates the total amount of people and assets directly damaged in case of a flood. On the one hand, population in the flood zone can change following households' relocation, the key feature of the MR group (100\% of papers), or zoning policies undertaken by Government, an actor usually included only in SH group (See 3.2.2). On the other hand, the amount of assets is estimated through land-value maps. When a housing market is modeled explicitly $(11: 12 \mathrm{MR}, 5: 18 \mathrm{SH})$, the land-value evolves endogenously as a product of household relocation decisions, leading to price differentials between flood-prone and safe zones. Alternatively, the dynamic land value might change through exogenous GDP projections (Haer et al., 2019), though not differentiating values between flood-prone vs. safe areas.

\subsubsection{Spatial and temporal scales}

Spatial scale is directly correlated with the amount of people and assets at risk. In flood-ABMs the spatial dimension ranges from a town up to a macro area such as regions or nation-states. Likewise, depending on the scope of the paper, the representation of space itself differs from a stylized landscape (McNamara \& Keeler, 2013; Walls et al., 2018) to raster (Mustafa et al., 2018) and vector-based maps (Filatova, 2015).

Within the MR group, 11:12 of articles focus on a city with flood-prone areas, with some models comparing two cities (Chandra-Putra \& Andrews, 2019; De Koning \& Filatova, 2020). Flood-ABMs from the SH community work 
at a variety of scales: from urban neighborhoods (Dubbelboer et al., 2017), counties (Han \& Peng, 2019), and islands (Abebe et al., 2019a, 2019b), to provincial regions (Mustafa et al. 2018) up to the entire European Union (Haer et al., 2019, 2020). The latter are the first attempts to scale-up these models to continental macro-areas, while still maintaining a high spatial resolution.

The majority of articles (25:28) use data or are based on empirical case-studies in developed countries such as Europe (13:28) or the US (11:28). Only three articles examine case studies in developing countries (Abebe et al., 2019a, 2019b; Hassani-Mahmooei \& Parris, 2012). This bias is likely due to data limitations in developing countries, especially regarding data on behavior and social interactions.

Risk propagates through time. Moreover, resilience encompasses the risk framework and the system ability to cope with a shock considering its capacity to learn, adapt, recover and self-organize. Therefore, the temporal dimension is crucial to capture critical transitions happening in such systems.

Temporal scales in flood-ABMs vary from around $25(M R)$ and $43(S H)$ years of simulations on average and up to 100 years (Haer et al., 2017). Instead of a fixed temporal horizon, some flood-ABMs establish it endogenously, for example, via market outcomes (Filatova et al., 2009; McNamara \& Keeler, 2013). The length of each time step is typically one year in 17 and 4 papers from the $S H$ and $M R$ groups respectively (Table 1). Alternatively, time steps can be semi-annual (de Koning \& Filatova, 2020; de Koning et al., 2017), monthly (Filatova, 2015; Haer et al., 2017; Hassani-Mahmooei \& Parris, 2012), or daily (Chandra-Putra \& Andrews, 2019). Thus, each group employs a scale that fits the phenomena of interest. The $\mathrm{SH}$ flood-ABMs focus on environmental processes that require longer time horizon and annual resolution. The $M R$ group uses shorter time horizon and resolution (Table 1) to emphasize social dynamics.

Moreover, while it is useful to develop models to match the temporal horizon of 50-100 years of physical flood models (Haer et al., 2017, 2019; McNamara \& Keeler, 2013; Mustafa et al., 2018), it raises a question about the escalating uncertainty of the socio-economic forecasts. In particular, relevant factors such as Household behavior, flood risk perceptions, preferences, and technological progress will likely change dramatically.

Table 1: Temporal scale in flood-ABMs. The numbers within the orange boxes represent the count of MR papers, while the numbers in the light-blue boxes indicate the count of $\mathrm{SH}$ articles.

\begin{tabular}{|c|c|c|c|c|c|c|c|c|}
\hline \multirow{2}{*}{ Time step } & \multicolumn{2}{|c|}{ Daily } & \multicolumn{2}{|c|}{ Monthly } & \multicolumn{2}{|c|}{ Semi-annual } & \multicolumn{2}{|c|}{ Yearly } \\
\hline & 1 & 0 & 4 & 1 & 3 & 0 & 4 & 17 \\
\hline \multirow{2}{*}{$\begin{array}{l}\text { Time horizon } \\
\text { (Years) }\end{array}$} & \multicolumn{2}{|c|}{ Endogenous } & \multicolumn{2}{|c|}{$<30$} & \multicolumn{2}{|c|}{$30-60$} & \multicolumn{2}{|c|}{$60<$} \\
\hline & 3 & 0 & 4 & 2 & 4 & 12 & 1 & 4 \\
\hline
\end{tabular}

\subsection{Learn-adapt cycle in flood-ABMs}

The learn-adapt cycle (Figure 1) covers the modeled actors endogenously (Figure 3), how they interact, the CCA actions they pursue, and how these actions might change over time through learning. Hence, it plays a central role in connecting incremental to transformative adaption, a crucial process to achieve CAS resilience (Wilson et al., 2020).

\subsubsection{Actors in flood-risk management and their interactions}

Households' micro-level behavior is the core component of flood-ABMs. Both $S H$ and MR groups employ Households' interactions to explore the potential of modeling societies from the bottom-up. The Household agents are heterogeneous in income, preferences, risk perception, and sometimes behavioral strategies. However, there is a clear distinction between $S H$ and $M R$ groups in how Households are modeled and the objectives they pursue. Households in the $M R$ group compete when choosing locations that offer different 
spatial tradeoffs between environmental amenities and disamenities. The choice of a spatial location is mediated through social institutions such as housing or land markets (11:12 of articles). Therefore, Households are divided into sub-groups that highlight their role in the market: buyers, sellers and homeowners (Filatova et al., 2009, 2011; McNamara \& Keeler, 2013; Walls et al., 2018). Households in the SH flood-ABMs act with a single purpose: to minimize future expected flood damages (Haer et al., 2019). Hence, they are typically not divided into sub-groups and do not compete for locations, unless property markets are modeled (5:18 of the cases).

Real estate is a common actor in MR flood-ABMs (Chandra-Putra \& Andrews, 2019; de Koning et al., 2017, 2019; de Koning \& Filatova, 2020; Filatova, 2015). The Real estate agent observes successful trades and identifies changes in market conditions, learning from hundreds of recent sales in the simulated decentralized housing market. Sellers then use this information to update price expectations in line with recent market trends. Therefore, this reinforces the Household's agents' learning process through prices that go up or down based on shifting local demand and supply due to changes in Households' preferences or risk perceptions.

Developer is a profit-maximizing agent whose role is to buy land from land-owners, based on housing demand and supply (Chandra-Putra \& Andrews, 2019; Dubbelboer et al., 2017; Walls et al., 2018). The Developer builds new houses and sells them to Households, enriching the urbanization process' representation either through the endogenous housing market or based on past exogenous data. In the former case, when a housing market institution is modeled, the Developer adds complexity and realism to the bilateral interactions between individual Households on the market (Jenkins et al., 2017; Magliocca \& Walls, 2018). In the latter case, different urbanization scenarios shaped by the Developer agent combined with planning authorities allow damages to evolve (Löwe et al. 2017; Mustafa et al. 2018). Scenarios based on past data (SH group) are a useful shortcut to represent changes in exposure but may appear misleading if urbanization is affected by increasing flood severity and likelihood.

About $50 \%$ of papers $(13: 28)$ explore the possibility of undertaking insurance either as a Household agent action (McNamara \& Keeler, 2013) or as a policy scenario (Chandra-Putra et al., 2015). However, usually, insurancerelated decisions remain simplistic, omit representing heterogeneity or learning, hence missing some of the principal advantages of ABMs. Only six cases (Table 2) model an Insurer that makes decisions endogenously: calculate premiums, offer discounts, collect, and pay out. The Insurer agent increases the complexity of flood risk and resilience dynamics through two channels. First, premiums can be parametrized in a sophisticated way, resembling the real-world schemes such as US NFIP (Chandra-Putra \& Andrews, 2019; Han \& Peng, 2019) or Flood Re (Crick et al., 2018). Second, an Insurer can interact with other agents in flood-ABMs; for instance, it can offer premium discounts to Households if they implement risk mitigation measures (Haer et al., 2017; Han \& Peng, 2019) or may engage in multi-level insurances schemes where Government re-insures risks above a certain threshold (Dubbelboer et al., 2017). The latter, in particular, offers the possibility to test several policy scenarios where premium affordability and an interplay between insurance and other long-term risk reduction policies are essential (Crick et al., 2018).

Starting from 2017, flood-ABMs usually include Government (Abebe et al., 2019b; Dubbelboer et al., 2017; Tonn et al., 2019), often alongside the Developer and Insurer agents. As before, we consider the Government as an agent only when it is coded as a separate entity with an endogenous decision-making process. As for the Insurer agent, there are cases where it is included as an exogeneous action (Erdlenbruch \& Bonté, 2018; Haer et al., 2016) or as a policy scenario (Chandra-Putra et al., 2015). The Government agent is a stylized representation of different policymakers from the state government to municipal planning authorities. Hence, it is a collective agent that acts at the macro level to maximize community welfare by reducing the overall risk. Its actions vary from evaluating and approving development proposals, to deciding whether to invest or not and where in flood protection measures such as dikes and levees (Haer et al., 2019; Michaelis et al., 2020; Tonn \& Guikema, 2018). Given the tradition of estimating floods risks with/without particular engineering protection measures inherent to the $\mathrm{SH}$ community, the Government is a common agent within the SH group (Table 2), compared to only one article in the $M R$ group (Chandra-Putra \& Andrews, 2019). The inclusion of Government permits testing of crossscale CCA strategies involving public and private adaptation (Haer et al., 2020; Han \& Peng, 2019) in the face of increasing risks.

Interactions between agents are the core feature of any computational model of behavioral change and societal dynamics. Agents can interact with each other, with collective agents and social institutions, and with the spatial environment (Figure 4). An ABM's complexity is contingent on the variety of agents being modeled and the type 
and intensity of interactions among them. In our analysis of the two literature streams we note several differences. While the $M R$ group tends to include fewer agents (Figure 3), interactions between them are modeled in a more sophisticated manner, with strong theoretical and empirical foundations as well as granular and shorter time dimensions (Table 1). The $\mathrm{SH}$ group tends to focus more on the diversity of agents, with only a few papers introducing any exchange of information - for example, about risks or effectiveness of CCA options - through social interactions between individual agents. Haer et al. (2017) introduce a probabilistic function that represents a process when Households get new information by talking with others or from the media. Erdlenbruch \& Bonté (2018) model information exchange among Households connected via small-world social networks, where the level of influence emerges through the endogenous formation of sub-networks. Alternatively, all Household agents within a specified spatial radius influence each other based on a distancedecay parameter (Chandra-Putra et al., 2015). Yet, due to the reduced spatial scale under consideration, some SH ABMs consider all agents as neighbors (Tonn et al., 2019; Tonn \& Guikema, 2018), with only one article that implements a social network structure at the regional level (Haer et al., 2016). The $M R$ group tends to focus on economic interactions, with spatial externalities directly affecting Households agents' decisions to locate (Filatova, 2015; Magliocca \& Walls, 2018) or what bid price to offer (de Koning \& Filatova, 2020). In particular, such interactions are included in all flood-ABMs with a housing market where Households compete for the same resource: housing/land. In this case, individual agents deal with the collective market institution (Figure 4), channeling individual interactions, and distributing resources by aligning demand and supply. The latter leads to endogenous variations in price signals and, ultimately, changing the attractiveness of locations.



Figure 4: Interactions and learning in flood-ABMs. The numbers in orange represent the count of MR papers, while the numbers in light-blue indicate the count of SH articles.

Notably, there is a tradeoff between the spatial extent and the complexity of collective institutions that reflects some modeling divergences between the two groups. On the one hand, articles belonging to the $\mathrm{SH}$ group that have a detailed spatial scale at the regional level do not forecast future urbanization through market interactions. They either entirely omit relocation or simply extrapolate future demand from past urbanization data (Löwe et al., 2017; Mustafa et al., 2018). On the other hand, within the MR group, the papers that model endogenous housing market and land value dynamics at the regional scale remain stylized (Magliocca \& Walls, 2018; Walls et al., 2018).

In both groups, Households interact with collective agents (i.e., Insurer or Government) following pre-defined regulatory rules that are always fixed during the simulation. For instance, these include the amount of damage covered by the Insurer or the Government approval ratio for development proposals (Dubbelboer et al., 2017). In flood-ABMs, Households take these rules as given, except a case when they choose whether to comply with such collective regulatory institutions (Abebe et al., 2019a, 2019b). 
The exchange of information among agents is fundamental to study beyond the incremental effect of individual CCA actions and how such actions can trigger path dependency processes that might result in long term societal resilience.

\subsubsection{Agents' actions and learning}

In computational ABMs, the above stakeholders are endowed with various actions to perform during the simulation. Some actors perform more complex decisions than others. Notably, the Real estate, Developer, and Insurer agents in flood-ABMs often have only one action (e.g., estimation of property values, building or selling houses), and a single behavioral strategy aimed at increasing profits or clearing the market. Therefore, we focus on Household and Government CCA actions because, in flood-ABMs, they often make multiple decisions. Although, responses from community and social initiatives are still lacking.

Actions of Households: in reality, households pursue a wide range of actions to cope with flood risks they face (Koerth et al., 2017). Assuming they remain in the same hazard-prone location, people can take on-site actions: either structural CCA measures (e.g., flood-proofing a house, physical installations, and modifications (ChandraPutra et al., 2015)) or non-structural measures (e.g., insurance). While on-site CCA can partially offset individual climate risks, in some cases, a relocation within or outside the hazardous area might be a more valuable option (Tonn et al., 2019). Flood-ABMs model all three types.

With its primary focus on dynamic vulnerability, the majority of flood-ABMs from the $S H$ community integrate some sort of structural CCA measures (17:18 of articles compared to 3:12 in the MR group). Many flood-ABMs include permanent building elevation as a measure to prevent damages with a given water level (Abebe et al., 2019b; Chandra-Putra et al., 2015; Han \& Peng, 2019; Tonn et al., 2019). Alternatively, Households agents can employ house-level flood barriers that reduce the damage partially (usually 70-80\%) (Haer et al., 2018; Michaelis et al., 2020) and can be combined with other measures (Haer et al., 2016, 2019, 2020). Structural measures are usually assumed to permanently alter a house, except one example of structural temporal measures that expire after seven years (Erdlenbruch \& Bonté, 2018). Household agents may also collaborate to implement community-level engineering measures (McNamara \& Keeler, 2013).

The most common non-structural CCA is insurance, included in 10:18 and 5:12 of the SH and MR groups' articles correspondingly. Moreover, there is a substantial difference in how insurance is modeled between the two groups, as defined by the type of stakeholders included in flood-ABMs. Indeed, when an Insurer agent is modeled, more complex insurance schemes are implemented. Flood-ABMs start to replicate the complexity of the actual insurance schemes, where the insurance premium is contingent on structural damage mitigation measures, incentives, or governmental subsidies. For instance, Households can get a discount if they adopt any of the aforementioned structural CCA measures (Haer et al., 2017; Han \& Peng, 2019). These incentives, coupled with structural CCA, are fundamental to exploit the role of insurance as a disaster risk reduction measure and not merely as a mechanism of risk transfer (Crick et al., 2018). The premium incentives are implemented in 8:18 papers that include insurance in the SH group against only two (Chandra-Putra et al., 2015; Chandra-Putra \& Andrews, 2019) in the $M R$ one. Furthermore, regarding non-structural adaptation measures, there are three cases (Michaelis et al., 2020; Tonn et al., 2019; Tonn \& Guikema, 2018) where households can fill a complaint and request a structural CCA by the Government.

When talking about relocation, there are significant differences between the two groups as for the other CCA actions. With location choice and land-use change being the focus of the $M R$ group, relocation is included in all articles and in 11:12 of the cases through housing markets. Hence, household interactions are mediated across the market process, which can be centralized (Chandra-Putra \& Andrews, 2019) or decentralized (de Koning \& Filatova, 2020; Filatova, 2015). Household agents form expectations, which incorporate advanced methods for the evolution of risk perceptions and market trends, also in response to floods (de Koning et al., 2017; Magliocca \& Walls, 2018). Thus, each round of Household agents' interactions will affect further price trends and future individual decisions, bringing transformational changes at the macro-level (i.e., price discount in the flood-prone area). Conversely, in the $S H$ group, Households agents primarily remain in the same location (11:18), hindering the opportunity to model outmigration as a CCA option. Relocation is triggered when a "risk threshold" is reached, causing Households to move out of the flood-prone area (Tonn et al., 2019; Tonn \& Guikema, 2018), or is modeled via a simplified housing market (Chandra-Putra et al., 2015; Crick et al., 2018; Dubbelboer et al., 2017; Jenkins et al., 2017; McNamara \& Keeler, 2013). 
Thus, the Households of the two groups mainly focus on risk components differently (Table 2). The MR group concentrates on the evolution of exposure linked to change in Household location decisions and land value. Conversely, the $\mathrm{SH}$ group focuses on Household structural CCA actions, transforming the static view on vulnerability, common in flood risk assessment (Aerts et al., 2018). Haer et al. ( 2017) find that risks are overestimated by $60 \%$ if Household adaptive behavior is ignored. Both aspects are important to understand the presence of tipping points that undermine CAS resilience. On the one hand, increasing hazard probabilities due to climate change may trigger a collapse of prices and outmigration from areas that have been previously attractive (de Koning \& Filatova, 2020). On the other hand, the cumulative effect of individual adaptation actions might impact urban resilience.

Table 2: Stakeholders and types of actions modeled in computation agent-based models concerning the hazard, exposure, and vulnerability components of flood risk. The numbers within the orange boxes represent the count of MR papers, while the numbers in the light-blue boxes indicate the count of $\mathrm{SH}$ articles.

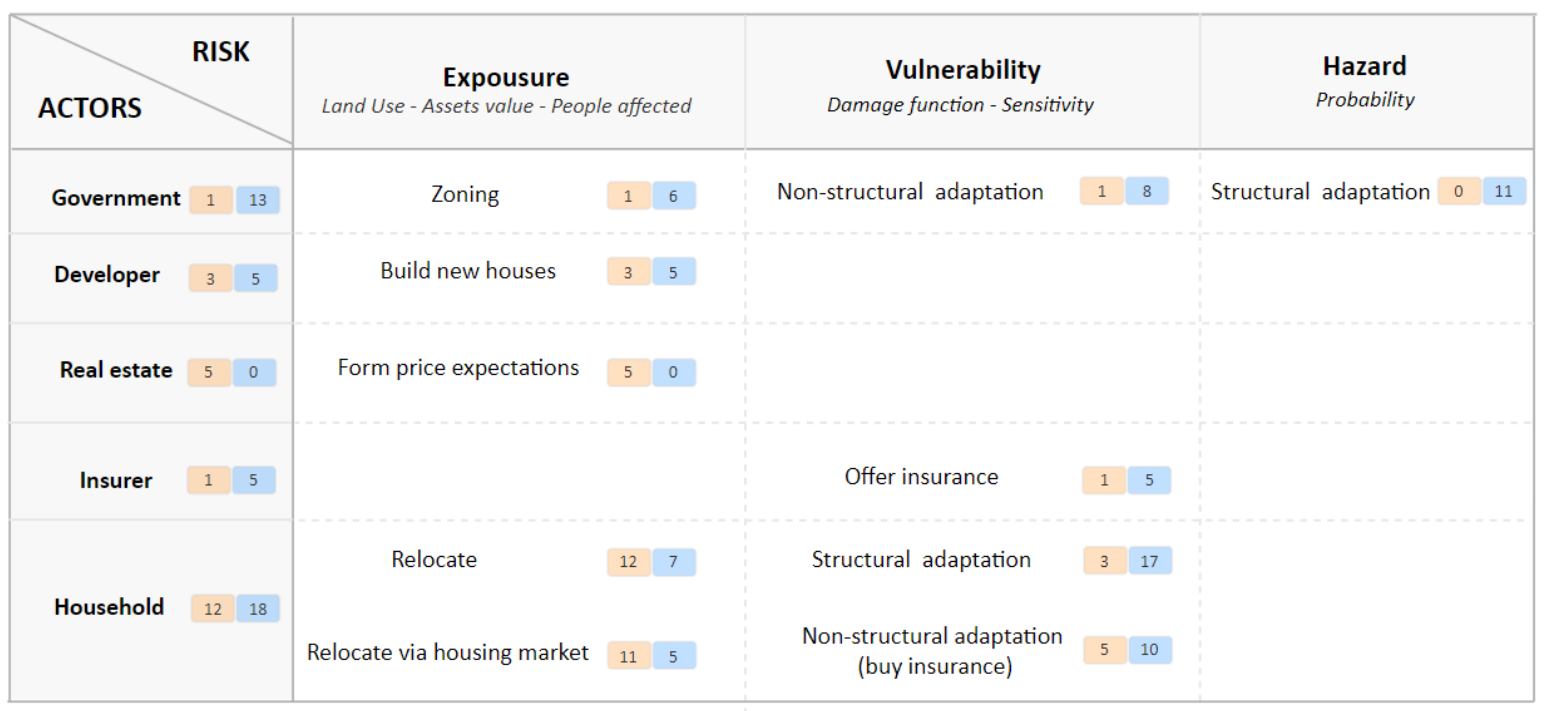

Actions of Government: at the macro level, governments can pursue structural (investments in large-scale physical flood-defenses) or non-structural measures (incentives for individual CCA behavior). As climate change intensifies, increasingly planned relocation and zoning come to the political agenda as CCA actions alter the hazard exposure.

Historically, governments protect their community by implementing structural measures that decrease the risk by reducing the hazard's probability. These measures are the most commonly implemented (Table 2) and include raising engineering infrastructure, such as dikes or levees, that protect entire regions (Haer et al., 2017, 2019; Michaelis et al., 2020; Tonn et al., 2019) or improving the drainage system of specific neighborhoods (Abebe et al., 2019b; Dubbelboer et al., 2017; Löwe et al., 2017).

Furthermore, Government agents can encourage private behavior and bottom-up adaptation with information campaigns (Erdlenbruch \& Bonté, 2018; Haer et al., 2016; Tonn et al., 2019) and can offer either a discount on insurance premiums (Han \& Peng, 2019) or a subsidy for individual structural measures (Abebe et al., 2019b; Jenkins et al., 2017; Löwe et al., 2017). Alternatively, Government can introduce regulations that force CCA actions such as setting a minimum height for new developments in certain areas (Abebe et al., 2019b; ChandraPutra \& Andrews, 2019; Crick et al., 2018). These measures affect the risk through the vulnerability component.

The government plays a crucial role in regulating developments in hazard-prone areas. Flood-ABMs capture this through zoning enforcement by government agents (Löwe et al., 2017; Mustafa et al., 2018). Alternatively, the Government issues building code requirements that guide new urban developments in flood-ABMs (Abebe et al., 2019a; Jenkins et al., 2017). This group of actions aims to manage the number of people and assets centrally at risk, thus addressing risk by reducing exposure. 
The coordinated anticipatory CCA actions undertaken by both Households and Government are necessary to tackle rising flood risks and deliver CAS resilience. In this aspect, the two groups employ a different approach, with a Government that is excluded in the $M R$ group.

Learning: either at the individual or collective level, the actions and interactions undertaken by agents might change and evolve during the simulation through learning, affecting further the learn-adapt cycle and, consequently, resilience. Indeed, agents learn when they "change their adaptive traits over time as a consequence of their experience" (Grimm et al., 2010). Agents gain information through their past actions or both direct and indirect interactions with other agents. They might use these experiences to update their decision strategies and pursue a behavior change (Figure 4). Furthermore, there are several ways to model how agents learn and adapt, with some overlaps as well as distinct characteristics between the two groups.

Within the SH group, 11:18 papers implement a learning process. For half of them, it is a gradual change in agent attributes when exchanging information with other agents or following their experience of certain events. When exchanging information, verbal persuasion or observational learning of actions taken within the household's social network can alter the probability to adapt by a fixed percent (Erdlenbruch \& Bonté, 2018; Haer et al., 2016). When Household agents experience a hazard event, their risk perception increases together with the willingness to adapt. In flood-ABMs, this learning process is modeled either via a linear change of Households' parameters by a static, fixed amount (Tonn et al., 2019; Tonn \& Guikema, 2018) or using a discontinuous function that depends on relative damages and a memory-decay rate (Michaelis et al., 2020).

Both $\mathrm{SH}$ and $\mathrm{MR}$ flood-ABMs share examples of Bayesian Learning employed to model the evolution of individual Households' risk perceptions. Haer et al. (2017) used Bayesian learning to update risk perception dynamically according to a bundle of different attributes such as flood experience, social and media influence, each with a different weight. Alternatively, Household agents observe the occurrence of a hazard event and update their expectations about future floods (Magliocca \& Walls, 2018) or their risk perception that affects an individual preference to avoid flood zones (de Koning \& Filatova, 2020).

All the papers with an endogenous housing market (Figure 4) model the formation of adaptive expectations when observing other agent actions and the overall market conditions. Depending on the excess of supply or demand in specific (flood-prone) neighborhoods, market interactions create spatial price differentials that affect Household agents' location decisions (de Koning \& Filatova, 2020). A practical example is when coastal residents begin to understand the impacts of climate change, and market outcomes reflect that understanding, leading to price change and further adjustments (Magliocca \& Walls, 2018). Since ABMs embrace bounded rationality (no optimization, no full information), agent predictions are not perfect. Yet, agents can learn from their mistakes through reinforcement learning algorithms and select a prediction method that reduces the cumulative errors over time (Walls et al., 2018). In the empirical housing market model, price expectations capture not only the temporal trend but also the attributes of a location. In the case when adaptive expectations are formed for different houses, the Real estate agent acts as a mediator who performs collective learning. To learn, the Real estate agent traces price changes based on specific spatial attributes, including the likelihood of flood and anticipated severity of the damage, by performing a hedonic price analysis of successful simulated transactions (de Koning et al., 2017; Filatova, 2015). The Real estate also learns by applying different learning strategies such as mean, projection, mirror, and regional models to capture the market dynamics and suggest a final price to sellers (Filatova, 2015). Otherwise, the task of collective learning is with the Developer agent that runs a hedonic price analysis on specific spatial attributes and directly provides sellers with an estimated value of their property (Chandra-Putra \& Andrews, 2019).

\subsubsection{Theories and data behind agents' decisions}

Theoretical micro-foundations: within the learn-adapt cycle, the complexity of agents' decision-making process varies. The Developer, Insurer, Real estate, and Government agents typically use simplistic behavioral strategies, lacking solid theoretical or empirical micro-foundations. At most, agents other than Households often rely on a version of a rational decision-maker and weigh costs and benefits of an action, though not always optimizing. The Developer maximizes expected profits (Dubbelboer et al., 2017), and the Insurer sets premiums dividing overall EAD by the number of Households (Haer et al., 2017) or attached to property characteristics (ChandraPutra \& Andrews, 2019; Han \& Peng, 2019). The Government agent reacts to specific events, e.g., a flood of a 
certain magnitude and damage (Tonn et al., 2019; Tonn \& Guikema, 2018), or performs a cost-benefit analysis of possible CCA actions (Haer et al., 2017, 2020; Löwe et al., 2017; Michaelis et al., 2020). An exception is the CLAIM flood-ABM (Abebe et al., 2019a, 2019b), which models regulatory institutions following the Institutional Analysis and Development framework (Ostrom et al.,1994). With respect to modeling Household behavior, flood-ABMs employ ad-hoc heuristics, Expected Utility theory, or behavioral theories.

Heuristic (ad hoc): despite the recent discussion on the need to ground individual households' decisions in social science theories (Schlüter et al., 2017), almost half of the flood-ABMs still employ ad hoc rules (Figure 5). This is particularly true within the $S H$ group (11:18) compared to the $M R$ group (4:12). Without explicit theoretical underpinnings, Household behavior is either guided by equations (Chandra-Putra et al., 2015; Dubbelboer et al., 2017; Hassani-Mahmooei \& Parris, 2012; McNamara \& Keeler, 2013; Mustafa et al., 2018) or depend on some "threshold" parameters (Abebe et al., 2019a, 2019b; Löwe et al., 2017; Tonn et al., 2019; Tonn \& Guikema, 2018).

Expected Utility (EU) is a popular socio-economic theory, especially within the $M R$ group (Figure 5). Stemming from urban economics, the $M R$ group borrows a formalization where households choose a location as a tradeoff between economic benefits and environmental amenities. Further, EU weights probabilistic losses in case a flood occurs, but importantly all flood-ABMs depart from the assumption of a fully-informed rational agent. Scholars model bounded rational agents by applying different subjective probabilities (Filatova et al., 2011; Magliocca \& Walls, 2018), by discounting expected utility (Haer et al., 2019, 2020) via overestimating/underestimating individual EU, or by modeling myopic Households that do not anticipate floods to intensify (de Koning \& Filatova, 2020).

Behavioral theories that study individual behavior under risk, including Prospect Theory (PT) (Kahneman \& Tversky, 1979) or Protection Motivation Theory (PMT) (Rogers, 1975), have been taken up by flood-ABMs only recently. PMT studies risky choices as a two-stage procedure - risk appraisal and coping appraisal - to understand that multiple factors affect risk perception, which influences individuals' decision-making process (adaptation or maladaptation). It is implemented in three $\mathrm{SH}$ articles, for example, to test the effects of flood risk communication strategies on individual CCA (Erdlenbruch \& Bonté, 2018; Haer et al., 2016). Michaelis et al. (2020) go further by pairing the two-stage procedure with different Households' CCA actions.

PT considers that individuals subjectively value probabilities and damages and that framing and loss aversion play a role when choosing between risky options. It is adopted by both $M R$ and $S H$ groups when modeling households' location decision (de Koning et al., 2017; de Koning \& Filatova, 2020) or when testing on-site CCA actions (Haer et al., 2017; Han \& Peng, 2019). Magliocca \& Walls (2018) employ PT extension, Salience Theory (Bordalo et al., 2012), to examine risk perception's role in shaping coastal development dynamics. In the $M R$ group PT is always compared to Expected Utility.

Testing alternative theories: since each theory assumes how people make choices under risk differently, it is essential to examine how the adoption of different theoretical assumptions might influence final results, other things being equal. Moreover, when different theories and behavioral hypotheses are tested, we acquire a more comprehensive understanding of the role that behavioral biases play in the dynamics of the coupled humanenvironment system. Overall, three articles within the $M R$ group (de Koning et al., 2017; de Koning \& Filatova, 2020; Magliocca \& Walls, 2018) and one in the SH (Haer et al., 2017) test different theoretical frameworks (Figure 5).

Nevertheless, the two groups' different theoretical approach mirrors how agents and floods interact (Figure 5). When households behave according to socio-economic theories such as EU or PT, future flood probability is always included within decision-making. Thus, they are forward-looking (11:12 in MR group) agents that though subjective and biased - anticipate future risks and account for the expected costs in their actions. Conversely, SH ABMs, largely employ an ad hoc decision-making process that makes agents backward-looking when considering CCA actions, reacting to floods they directly experience. In these cases, the natural hazard module runs at the beginning of the simulation and influences agents' subsequent behavior (Dubbelboer et al., 2017; Tonn et al., 2019). 
MR

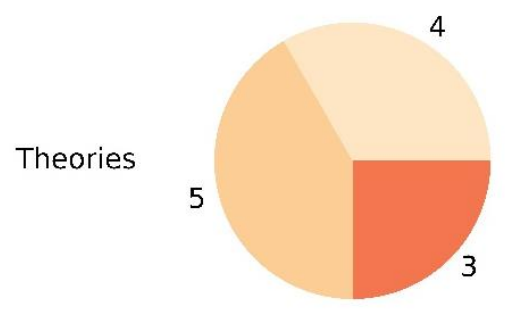

4

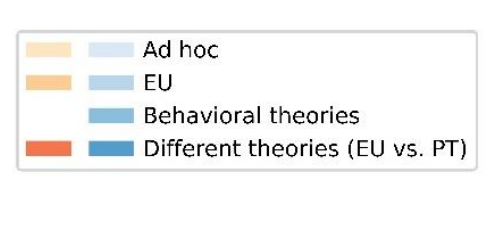

Expectations

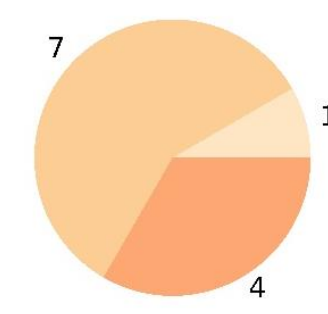

$\mathrm{SH}$
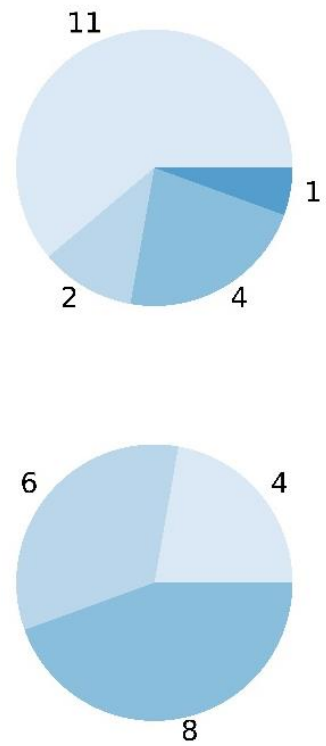

Figure 5: Theoretical micro foundations of agents' decisions and expectations in flood-ABMs.

Micro-level data behind agents' behavior: all articles reviewed have agents endowed with different socioeconomic and behavioral characteristics. The former are usually retrieved from aggregate socio-demographic data, such as Census, and disaggregated at the individual level. While this data is readily available, it rarely links to the fundamental processes driving agents' decisions in the flooding context. Agents' choices under risk are mainly driven by behavioral factors such as individual preferences (i.e., environmental amenities), subjective risk perception, or self-efficacy, which are challenging to quantify. Hence, flood-ABMs commonly use secondary literature to parameterize these behavioral factors (Dubbelboer et al., 2017; Filatova, 2015; Haer et al., 2017). Alternatively, scholars can calibrate behavioral parameters based on expert judgments (Abebe et al., 2019b; Michaelis et al., 2020; Tonn et al., 2019; Tonn \& Guikema, 2018).

Yet, secondary data may not represent the population under study, and preferences may have also changed over time. Hence, to capture behavioral dynamics, scientists use surveys, lab experiments, or participatory workshops designed for the specific population (Smajgl et al., 2011). Using a mail survey to estimate households' subjective risk perceptions (Filatova et al., 2011) show that the average subjective risk perception is misleading and that the distribution of perceptions within a population matter for the exposure dynamics in flood-ABMs. Relying on the behavioral traits elicited from a household survey, de Koning \& Filatova (2020) demonstrate that buyers and sellers treat information about flood risks differently and switch behavioral strategies from EU-driven to risk avoidance when experiencing a flood. Erdlenbruch \& Bonté (2018) show that optimal flood communication strategies differ when their empirical flood-ABMs relies on the secondary instead of primary data.

Besides survey data on hypothetical choices, flood-ABMs can employ primary data on actual options. For example, all RHEA models use real housing transaction data before and after hurricanes to specify the price expectations of Real estate agents as well as location preferences of Household agents (de Koning et al., 2017; Filatova, 2015). Empirical data is crucial in determining the behavioral strategies for agents' decisions, interactions, or learning. However, only one paper uses such data to model learning through social networks (Erdlenbruch \& Bonté, 2018). To specify agents' interactions, flood-ABMs also use semi-structured interviews (Filatova, 2015).

\subsection{Recovery and reorganization}

Within flood-ABMs, we identify three types of feedbacks: social, economic, and financial. The most well-defined social feedback is the safe-development paradox (Di Baldassarre et al., 2015). Improvements in flood defenses increase the sense of security among the population living in the floodplain and trigger a further increase of 
people and assets at risk. Only one article in the $S H$ group explores this paradox in an ABM that connects population growth and the occurrence of flood events (Haer et al., 2020). Rapid urbanization combined with the climate-driven increase in hazard severity and probability may lead to a major disaster, especially for cases with currently low probabilities and high impacts.

Economic feedbacks enter flood-ABMs through housing markets. Hence, they are at the core of the MR group. Agents' endogenous changes in preferences and perceptions influence prices and value at risk, leading to pathdependency and market sorting. When coastal residents begin to understand the impacts of climate change, and markets begin to reflect this in prices, low-income households become locked in hazard-prone areas (de Koning \& Filatova, 2020; Magliocca \& Walls, 2018).

Another critical feedback concerns the role of insurance and financial resilience. Insurance is commonly used as a pure risk transfer mechanism. However, empirical literature reports unintended consequences such as subsidizing developments in flood-prone areas that lead to an excessive tax burden for the rest of the society or to unaffordable premiums (Bagstad et., 2007; Crick et al., 2018). Therefore, government-subsidized insurance schemes have positive effects in the short term (affordability and uptake), but create unintended consequences in the long run. Flood-ABMs are increasingly used to trace these distributional impacts when the Insurer is modeled as a decision-making agent (Chandra-Putra \& Andrews, 2019; Crick et al., 2018; Han \& Peng, 2019). When insurance premiums are contingent on the implementation of structural adaptation measures, it not only enhances financial resilience in the short-term but leads to reduced vulnerability and stable premiums.

Recovery: empirical literature on resilience assessment operates with indicators of socio-economic resilience capturing inequality (Cutter et al., 2003; Linkov et al., 2013). Since flood-ABMs employ heterogeneous agents, they may potentially trace the dynamics in financial or social capitals across scales in the $5 \mathrm{C}-4 \mathrm{R}$ terms (Campbell et al., 2019) or economic and institutional resilience in BRIC/DROP terms (Cutter \& Derakhshan, 2019). Yet, flood-ABMs hardly highlight the impact of socio-economic heterogeneity on recovery from a natural disaster. Moreover, CCA's affordability is often overlooked in flood-ABMs that omit budget constraints at the agent level, 8:18, and 3:12 in the $S H$ and $M R$ group correspondingly. With budget constraints, flood-ABMs show differences in the implementation of CCA measures among income groups (Han \& Peng, 2019) and reveal climate gentrification that undermines urban resilience (de Koning \& Filatova, 2020). Walsh and Hallegatte (2019), a pioneer in quantifying socio-economic resilience in an ABM by translating flood damages into wellbeing losses while differentiating among income groups. Eid and El-Adaway $(2017,2018)$ employ resilience indices to study a recovery after a tornado. Hence, it should also be feasible to integrate them into flood-ABMs. Employment opportunities are another critical factor of a successful recovery, included in most socio-economic indicators of resilience (Cutter \& Derakhshan, 2019). However, the backbone of regional resilience and recovery - the role of firms that provide households with jobs and income - is entirely overlooked in flood-ABMs. Flood-ABMs could learn from the first attempts to incorporate firms' behavior in ABMs in response to other hazards (Eid et al., 2017; Eid \& El-Adaway, 2018) and immediate disaster response (Coates et al., 2016, 2019).

\section{Conclusions}

There is a growing recognition that socio-environmental systems models need to include behaviorally-rich and dynamic representations of human actors (Schill et al., 2019). This is especially important for climate change models where societies and economies are inadequately represented (Stern 2016; Gilligan 2018). The critical role of social interactions in influencing adaptation behavior in the real world is increasingly recognized (Wilson et al., 2020). The acknowledgment of the crucial role that human actors play in altering flood-prone cities' risks and resilience drives a paradigm shift in climate risk assessments. This influence can be seen in the proliferation of recently built computational models that explicitly include diverse socio-economic actors. Our systematic literature review analyzes 28 flood-ABMs, distinguishing between ABMs stemming from economics \& behavioral sciences and hydrology. We find that the two groups look at risk components and at the ability of a socioeconomic system to cope with flooding from distinct perspectives (Figure 6). Likewise, they address the key CAS resilience elements, such as adaptation, interactions, and learning, differently (Figure 6). Most flood-ABMs focus on households while representing decisions of government, insurers, and urban developers simplistically. A few flood-ABM in both groups focus on the long-term recovery and reorganizational element of resilience, which often implies combining modeling of individual actions and changes in social institutions (formal like markets or 
regulations, and informal like social norms), groups of actors and networks of organizations. Thus, the crucial transition from incremental to transformative adaption is still lacking.
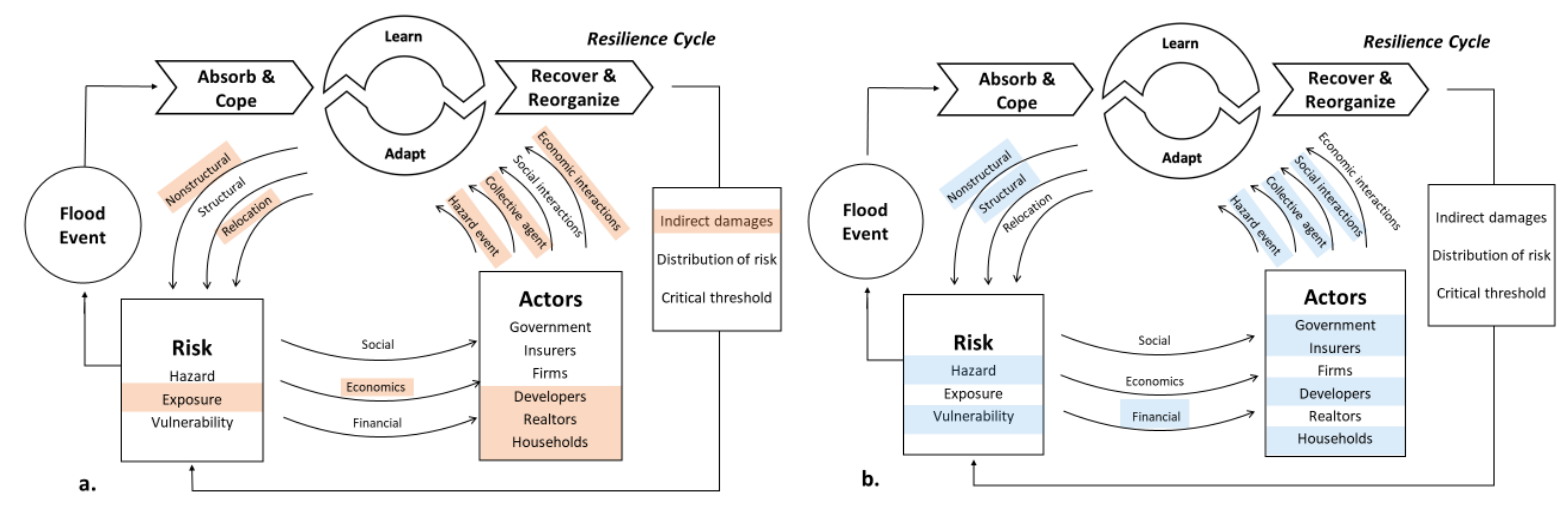

Figure 6: CAS resilience in flood-ABMs. Panels (a) and (b) reflect the key focus areas of the MR and SH groups correspondingly, as discusses in Section 3 above.

Learning from the current advances in flood-ABMs, the review identifies the following directions for future research.

Learning across disciplinary views: we call for adopting a multidisciplinary and complementary approach, that reconciles the merits of the $M R$ and $S H$ groups, improving their possibilities to trace CAS resilience. The $S H$ community's advances represent a vast pool of stakeholders and dynamic vulnerability (Figure 6b) due to onsite structural CCA in computational ABMs and integration with natural hazard modeling (hydrology, depthdamage curves). While the MR ABMs are firmly grounded in socio-economic theories and data to support agents' decisions and interactions, and model collective social institutions to capture dynamics in exposure and capital at risk endogenously (Figure 6a). The successful examples of the integration of the two views - Chandra-Putra et al. (2015) and Dubbelboer et al. (2017) - illustrate the feasibility and need to make some tradeoffs and simplifications. To measure the evolution of both prices and EAD, both articles introduced a simplified form of the housing market. The interdisciplinary dialog can be further supported by promoting reuse of code via openaccess libraries and the modular approach to designing ABMs (Bell et al., 2015). Yet, significant progress is still due in the reproducibility of flood-ABMs. Only 35\% use the ODD protocol (Grimm et al., 2020), and code is open access in less than $20 \%$ of the cases (Abebe et al., 2019b; De Koning \& Filatova, 2020; Dubbelboer et al., 2017; Filatova, 2015; Walls et al., 2018).

Behavioral theories and empirical data for agents' decisions: a transition from a representative rational agent to diverse behaviorally-rich actors in computational models may take various pathways. Social sciences offer a rich set of theories and empirical evidence on behavioral change, decisions under uncertainty, and factors influencing CCA decisions (Koerth et al., 2017; Noll et al., 2020) that can make this process scientifically sound. Still, 13:28 articles report flood-ABMs that use ad hoc rules to model behavioral change and social dynamics, undermining the call of the ABM community to have solid theoretical micro foundations (Schlüter et al., 2017). Regarding Household agents, most flood-ABMs go beyond perfect rationality either by employing behavioral theories or relaxing the perfect information condition for decisions driven by Expected Utility (e.g., via information asymmetry, myopia, subjective perceptions, or social influence). Therefore, bounded rationality prevails among theory-driven Household agents. Flood-ABMs rarely compare competing theories' performance and tend to 'grandfather' theories used for that class of decision making earlier, overlooking advances in psychological research. Hence, we recommend to compare different theories and test ABMs with different theoretical micro-foundations against empirical macro patterns (de Koning et al., 2017). Other agents in floodABMs - Government, Developer, Insurer - usually follow ad hoc rules or rely on rational decision making, leaving room for improvements. While social sciences offer a rich theoretical basis for modeling, these collective agents and social institutions they represent, are sparsely employed in computational models of CCA. Using more robust theories to manifest agents would allow a more in-depth analysis of the interactions: an underlying component in resilience. 
Notably, only three flood-ABMs use case-specific micro-level data to support modeling of agents' actions and interactions; the majority still relies on secondary literature data or expert judgments, if any. Using aggregate data to estimate critical behavioral parameters such as preferences or risk perceptions in flood-ABMs may mislead policy (Erdlenbruch \& Bonté, 2018). Flood-ABMs need to go beyond employing the data on the physical side and leverage the rich data from CCA studies in the future. Importantly, one needs to think about designing the data collection since adaptation to the 'new normal' foresees choices in response to events of intensity and frequency that humanity has not experienced for thousands of years.

Indirect damages and role of firms: flood-ABMs largely focus on estimating direct damages, with some models capturing relocation and changes in housing prices, but mainly overlooking other indirect effects. Yet, indirect damages, including business interruption, losses of employment opportunities, and tax revenues, may be higher than direct losses (Rodríguez et al., 2018). They could significantly exacerbate total risks beyond acceptable levels, bringing societies over the tipping points along climate adaptation pathways (Haasnoot et al., 2013) crucial for resilience. Quantitative metrics of socio-economic resilience (Cutter \& Derakhshan, 2019) or wellbeing losses (Walsh \& Hallegatte, 2019) commonly include employment opportunities, stressing the critical role of firms. Yet, none of the reviewed flood-ABMs include firms as agents (Figure 6). The inclusion of firms would extend the existing risk framework beyond a change in hazard, exposure, and vulnerability towards dynamic resilience assessment.

Heterogeneity within agent groups and evolution of resilience: we find that core-characteristics of resilience the ability to learn, adapt and recover and reorganize from a shock - are gradually adopted in flood-ABMs, yet the full power of complex adaptive systems remains underexplored. Additionally, components of coupled systems are rarely equally vulnerable (Turner et al. 2003). While ABMs are designed to capture heterogeneity, most flood-ABMs only report aggregated damages, prices, or adoption rates of CCA actions for entire populations and regions. Attempts to explore the distribution of risks and CCA actions across different socioeconomic groups are scarce. The models that do so, do not yet capture risk levels among different sections of the community. Does risk reduction for high-income groups leave low-income groups more vulnerable? Failing to report the distributional impacts in flood-ABMs misrepresents the scope and limits of adaptation and hinders the monitoring of socio-economic resilience over time. Finally, these generalizations have similar drawbacks to using the single 'representative-actor' and fail to utilize one of ABM's greatest strength: analysis of heterogeneity.

From incremental to transformational adaptation: the ramifications of climate change expose the limits of traditional CCA, making transformational adaptation only a question of households' actions (insurance uptake, flood-proofing houses, small scale relocation), hardly looking into transformational actions that include new radical changes in societal responses to hazards. That being said, ABMs can incorporate dynamic social institutions, trace cross-scale feedbacks, and capture non-linear dynamics that instigate transformational CCA (Wilson et al., 2020). Modeling transformational CCA with ABMs could be a natural extension and inherent part of 'reorganization' in Figure 1.

A complex adaptive systems approach that is grounded in social science theories and behavioral data, covers various stakeholders, including firms, traces heterogeneity of risk distribution, and includes modeling of dynamic behavior and institutions essential to trace the emergence of transformational CCA should be the way forward. One of the main challenges in addressing climate change lies in integrating information, knowledge, experiences, and collaborative projects involving scientists, practitioners, and policymakers from different disciplines. Resilience is an emerging theme in the climate policy domain that provides a systems perspective to structure a multi-community discussion. Therefore, we argue for a resilience-based dialogue to strengthen collaboration significantly and facilitate learning and information exchange across disciplines.

\section{Acknowledgments}

This work was supported by the European Research Council (ERC) under the European Union's Horizon 2020 Research and Innovation Program (grant agreement number: 758014). The authors are thankful to the 3 reviewers for their helpful and constructive feedback. 


\section{References}

Abebe, Y. A., Ghorbani, A., Nikolic, I., Vojinovic, Z., \& Sanchez, A. (2019a). A coupled flood-agent-institution modelling (CLAIM) framework for urban flood risk management. Environmental Modelling and Software, 111, 483-492. https://doi.org/10.1016/j.envsoft.2018.10.015

Abebe, Y. A., Ghorbani, A., Nikolic, I., Vojinovic, Z., \& Sanchez, A. (2019b). Flood risk management in Sint Maarten - A coupled agent-based and flood modelling method. Journal of Environmental Management, 248, 109317. https://doi.org/10.1016/j.jenvman.2019.109317

Adger, W. N., Arnell, N. W., \& Tompkins, E. L. (2005). Successful adaptation to climate change across scales. Global Environmental Change, 15(2), 77-86. https://doi.org/10.1016/j.gloenvcha.2004.12.005

Aerts, J. C. J. H., Botzen, W. J. W., Clarke, K. C., Cutter, S. L., Hall, J. W., Merz, B., Michel-Kerjan, E., Mysiak, J., Surminski, S., \& Kunreuther, H. (2018). Integrating human behaviour dynamics into flood disaster risk assessment. Nature Climate Change, 8(3), 193-199. https://doi.org/10.1038/s41558-018-0085-1

Bagstad, K. J., Stapleton, K., \& D’Agostino, J. R. (2007). Taxes, subsidies, and insurance as drivers of United States coastal development. Ecological Economics, 63(2-3), 285-298. https://doi.org/10.1016/j.ecolecon.2006.09.019

Bamberg, S., Masson, T., Brewitt, K., \& Nemetschek, N. (2017). Threat, coping and flood prevention - A meta-analysis. Journal of Environmental Psychology, 54, 116-126. https://doi.org/10.1016/j.jenvp.2017.08.001

Bayer, J., Atreya, A., Campbell, K., Botzen, W., \& Collier, B. (2014). Operationalizing Resilience against Natural Disaster Risk: Opportunities, Barriers, and a Way Forward. http://repo.floodalliance.net/jspui/handle/44111/2709

Bell, A. R., Robinson, D. T., Malik, A., \& Dewal, S. (2015). Modular ABM development for improved dissemination and training. Environmental Modelling and Software, 73, 189-200. https://doi.org/10.1016/j.envsoft.2015.07.016

Bordalo, P., Gennaioli, N., \& Shleifer, A. (2012). Salience Theory of Choice Under Risk. The Quarterly Journal of Economics, 127(3), 1243-1285. https://doi.org/10.1093/qje/qjs018

Campbell, K. A., Laurien, F., Czajkowski, J., Keating, A., Hochrainer-Stigler, S., \& Montgomery, M. (2019). First insights from the Flood Resilience Measurement Tool: A large-scale community flood resilience analysis. International Journal of Disaster Risk Reduction, 40, 101257. https://doi.org/10.1016/j.ijdrr.2019.101257

Chandra-Putra, H., \& Andrews, C. (2019). An integrated model of real estate market responses to coastal flooding. Journal of Industrial Ecology, 24(2), 424-435. https://doi.org/10.1111/jiec.12957

Chandra-Putra, H., Zhang, H., \& Andrews, C. (2015). Modeling real estate market responses to climate change in the coastal zone. Journal of Artificial Societies and Social Simulation, 18(2), 18. https://doi.org/10.18564/jasss.2577

Coates, G., Li, C., Ahilan, S., Wright, N. G., \& Alharbi, M. (2019). Agent-based modeling and simulation to assess flood preparedness and recovery of manufacturing small and medium-sized enterprises. Engineering Applications of Artificial Intelligence, 78, 195-217. https://doi.org/10.1016/j.engappai.2018.11.010

Coates, G., Li, C., Wright, N. G., \& Ahilan, S. (2016). Investigating the flood responsiveness of small and medium enterprises using agent-based modelling and simulation. International Journal of Safety and Security Engineering, 6(3), 627-635. https://doi.org/10.2495/SAFE-V6-N3-627-635

Crick, F., Jenkins, K., \& Surminski, S. (2018). Strengthening insurance partnerships in the face of climate change - Insights from an agent-based model of flood insurance in the UK. Science of the Total Environment, 636, 192-204. https://doi.org/10.1016/j.scitotenv.2018.04.239

Cutter, S. L., Boruff, B. J., \& Shirley, W. L. (2003). Social vulnerability to environmental hazards. Social Science Quarterly, 84(2), 242-261. https://doi.org/10.1111/1540-6237.8402002

Cutter, S. L., \& Derakhshan, S. (2019). Implementing Disaster Policy: Exploring Scale and Measurement Schemes for Disaster Resilience, Journal of Homeland Security and Emergency Management, 16(3), 20180029. https://doi.org/10.1515/jhsem-2018-0029

Dawson, R. J., Peppe, R., \& Wang, M. (2011). An agent-based model for risk-based flood incident management. Natural Hazards, 59(1), 167-189. https://doi.org/10.1007/s11069-011-9745-4

De Koning, K., \& Filatova, T. (2020). Environmental Research Letters LETTER • OPEN ACCESS Repetitive floods intensify outmigration and climate gentrification in coastal cities. https://doi.org/10.1088/1748-9326/ab6668

de Koning, K., Filatova, T., \& Bin, O. (2017). Bridging the Gap Between Revealed and Stated Preferences in Flood-prone Housing Markets. Ecological Economics, 136, 1-13. https://doi.org/10.1016/j.ecolecon.2017.01.022

de Koning, K., Filatova, T., \& Bin, O. (2019). Capitalization of Flood Insurance and Risk Perceptions in Housing Prices: An Empirical Agent-Based Model Approach. Southern Economic Journal, 85(4), 1159-1179. https://doi.org/10.1002/soej.12328

Di Baldassarre, G., Viglione, A., Carr, G., Kuil, L., Salinas, J. L., \& Blöschl, G. (2013). Socio-hydrology: conceptualising humanflood interactions. Hydrology and Earth System Sciences, 17(8), 3295-3303. https://doi.org/10.5194/hess-17-32952013

Di Baldassarre, G., Viglione, A., Carr, G., Kuil, L., Yan, K., Brandimarte, L., \& Blöschl, G. (2015). Debates - Perspectives on sociohydrology: Capturing feedbacks between physical and social processes. Water Resources Research, 51(6), 4770-4781. https://doi.org/10.1002/2014WR016416

Dubbelboer, J., Nikolic, I., Jenkins, K., \& Hall, J. W. (2017). An agent-based model of flood risk and insurance. Journal of Artificial Societies and Social Simulation, 20(1), 6. https://doi.org/10.18564/jasss.3135

Eid, M. S., \& El-Adaway, I. H. (2017). Integrating the Social Vulnerability of Host Communities and the Objective Functions of Associated Stakeholders during Disaster Recovery Processes Using Agent-Based Modeling. Journal of Computing in 
Civil Engineering, 31(5), 1-15. https://doi.org/10.1061/(ASCE)CP.1943-5487.0000680

Eid, M. S., \& El-Adaway, I. H. (2018). Decision-Making Framework for Holistic Sustainable Disaster Recovery : Agent-Based Approach for Decreasing Vulnerabilities of the Associated Communities. Journal of Infrastructure Systems, 24(3), 124. https://doi.org/10.1061/(ASCE)IS.1943-555X.0000427

Eid, M. S., El-Adaway, I. H., \& Asce, M. (2017). Sustainable disaster recovery: Multiagent-based model for integrating environmental vulnerability into decision-making processes of the associated stakeholders. Journal of Urban Planning and Development, 143(1). https://doi.org/10.1061/(ASCE)UP.1943-5444.0000349

Elsawah, S., Filatova, T., Jakeman, A. J., Kettner, A. J., Zellner, M. L., Athanasiadis, I. N., Hamilton, S. H., Axtell, R. L., Brown, D. G., Gilligan, J. M., Janssen, M. A., Robinson, D. T., Rozenberg, J., Ullah, I. I. T., \& Lade, S. J. (2020). Eight grand challenges in socio-environmental systems modeling. Socio-Environmental Systems Modelling, 2, 16226. https://doi.org/10.18174/sesmo.2020a16226

Erdlenbruch, K., \& Bonté, B. (2018). Simulating the dynamics of individual adaptation to floods. Environmental Science and Policy, 84, 134-148. https://doi.org/10.1016/j.envsci.2018.03.005

Fankhauser, S., Smith, J. B., \& Tol, R. S. J. (1999). Weathering climate change: Some simple rules to guide adaptation decisions. Ecological Economics, 30(1), 67-78. https://doi.org/10.1016/S0921-8009(98)00117-7

Field, C., Barros, V., Dokken, D., \& Mach, K. (2017). Climate Change 2014: Impacts, Adaptation, and Vulnerability. Part A: Global and Sectoral Aspects. Contribution of Working Group II to the Fifth. http://wedocs.unep.org/xmlui/handle/20.500.11822/15524

Filatova, T. (2015). Empirical agent-based land market: Integrating adaptive economic behavior in urban land-use models. Computers, Environment and Urban Systems, 54, 397-413. https://doi.org/10.1016/j.compenvurbsys.2014.06.007

Filatova, T., Parker, D. J., \& Van Der Veen, A. (2011). The implications of skewed risk perception for a dutch coastal land market: Insights from an agent-based computational economics model. Agricultural and Resource Economics Review, 40(3), 405-423. https://doi.org/10.1017/S1068280500002860

Filatova, T., Van Der Veen, A., Parker, D. J., \& Veen, A. Van Der. (2009). Land Market Interactions between Heterogeneous Agents in a Heterogeneous Landscape - Tracing the Macro-Scale Effects of Individual Trade-Offs between Environmental Amenities and Disamenities. Canadian Journal of Agricultural Economics, 57(4), 431-457. https://doi.org/10.1111/j.1744-7976.2009.01164.x

Filatova, T., Verburg, P. H., Parker, D. J., \& Stannard, C. A. (2013). Spatial agent-based models for socio-ecological systems: Challenges and prospects. Environmental Modelling and Software, 45, 1-7. https://doi.org/10.1016/j.envsoft.2013.03.017

Folke, C. (2006). Resilience: The emergence of a perspective for social-ecological systems analyses. Global Environmental Change, 16(3), 253-267. https://doi.org/10.1016/j.gloenvcha.2006.04.002

Grimm, V., \& Berger, U. (2016). Structural realism, emergence, and predictions in next-generation ecological modelling: Synthesis from a special issue. Ecological Modelling, 326, 177-187. https://doi.org/10.1016/j.ecolmodel.2016.01.001

Grimm, V., Berger, U., DeAngelis, D. L., Polhill, J. G., Giske, J., \& Railsback, S. F. (2010). The ODD protocol: A review and first update. Ecological Modelling, 221(23), 2760-2768. https://doi.org/10.1016/j.ecolmodel.2010.08.019

Grimm, V., Railsback, S. F., Vincenot, C. E., Berger, U., Gallagher, C., Deangelis, D. L., Edmonds, B., Ge, J., Giske, J., Groeneveld, J., Johnston, A. S. A., Milles, A., Nabe-Nielsen, J., Polhill, J. G., Radchuk, V., Rohwäder, M. S., Stillman, R. A., Thiele, J. C., \& Ayllón, D. (2020). The ODD protocol for describing agent-based and other simulation models: A second update to improve clarity, replication, and structural realism. Journal of Artificial Societies and Social Simulation, 23(2), 7. https://doi.org/10.18564/jasss.4259

Groeneveld, J., Müller, B., Buchmann, C. M., Dressler, G., Guo, C., Hase, N., Hoffmann, F., John, F., Klassert, C., Lauf, T., Liebelt, V., Nolzen, H., Pannicke, N., Schulze, J., Weise, H., \& Schwarz, N. (2017). Theoretical foundations of human decisionmaking in agent-based land use models - A review. Environmental Modelling and Software, 87, 39-48. https://doi.org/10.1016/j.envsoft.2016.10.008

Haasnoot, M., Kwakkel, J. H., Walker, W. E., \& ter Maat, J. (2013). Dynamic adaptive policy pathways: A method for crafting robust decisions for a deeply uncertain world. Global Environmental Change, 23(2), 485-498. https://doi.org/10.1016/j.gloenvcha.2012.12.006

Haer, T., Botzen, W. J. W., \& Aerts, J. C. J. H. (2016). The effectiveness of flood risk communication strategies and the influence of social networks-Insights from an agent-based model. Environmental Science and Policy, 60, 44-52. https://doi.org/10.1016/j.envsci.2016.03.006

Haer, T., Botzen, W. J. W., \& Aerts, J. C. J. H. (2019). Advancing disaster policies by integrating dynamic adaptive behaviour in risk assessments using an agent-based modelling approach. Environmental Research Letters, 14(4), 044022. https://doi.org/10.1088/1748-9326/ab0770

Haer, T., Botzen, W. J. W., de Moel, H., \& Aerts, J. C. J. H. (2017). Integrating Household Risk Mitigation Behavior in Flood Risk Analysis: An Agent-Based Model Approach. Risk Analysis, 37(10), 1977-1992. https://doi.org/10.1111/risa.12740

Haer, T., Botzen, W. J. W., Van Roomen, V., Connor, H., Zavala-Hidalgo, J., Eilander, D. M., \& Ward, P. J. (2018). Coastal and river flood risk analyses for guiding economically optimal flood adaptation policies: A country-scale study for Mexico. Philosophical Transactions of the Royal Society A: Mathematical, Physical and Engineering Sciences, 376(2121), 20170329. https://doi.org/10.1098/rsta.2017.0329

Haer, T., Husby, T. G., Botzen, W. J. W., \& Aerts, J. C. J. H. (2020). The safe development paradox: An agent-based model for flood risk under climate change in the European Union. Global Environmental Change, 60, 102009. https://doi.org/10.1016/j.gloenvcha.2019.102009 
Han, Y., \& Peng, Z. ren. (2019). The integration of local government, residents, and insurance in coastal adaptation: An agentbased modeling approach. Computers, Environment and Urban Systems, 76, 69-79. https://doi.org/10.1016/j.compenvurbsys.2019.04.001

Hassani-Mahmooei, B., \& Parris, B. W. (2012). Climate change and internal migration patterns in Bangladesh: An agent-based model. Environment and Development Economics, 17(6), 763-780. https://doi.org/10.1017/S1355770X12000290

Jenkins, K., Surminski, S., Hall, J. W., \& Crick, F. (2017). Assessing surface water flood risk and management strategies under future climate change: Insights from an Agent-Based Model. Science of the Total Environment, 595, $159-168$. https://doi.org/10.1016/j.scitotenv.2017.03.242

Jha, A., Lamond, J., Bloch, R., Bhattacharya, N., Lopez, A., Papachristodoulou, N., Bird, A., Proverbs, D., Davies, J., \& Barker, R. (2011). Five Feet High and Rising Cities and Flooding in the 21 st Century. The World Bank. https://doi.org/10.1596/1813-9450-5648

Kahneman, D., \& Tversky, A. (1979). Prospect theory: An analysis of decision under risk. Econometrica, 47, 278. https://doi.org/10.2307/1914185

Koerth, J., Vafeidis, A. T., \& Hinkel, J. (2017). Household-Level Coastal Adaptation and Its Drivers: A Systematic Case Study Review. Risk Analysis, 37(4), 629-646. https://doi.org/10.1111/risa.12663

Kremmydas, D., Athanasiadis, I. N., \& Rozakis, S. (2018). A review of Agent Based Modeling for agricultural policy evaluation. Agricultural systems, 164, 95-106. https://doi.org/10.1016/j.agsy.2018.03.010

Latombe, G., Parrott, L., \& Fortin, D. (2011). Levels of emergence in individual based models: Coping with scarcity of data and pattern redundancy. Ecological Modelling, 222(9), 1557-1568. https://doi.org/10.1016/j.ecolmodel.2011.02.020

Linkov, I., Eisenberg, D. A., Bates, M. E., Chang, D., Convertino, M., Allen, J. H., Flynn, S. E., \& Seager, T. P. (2013). Measurable resilience for actionable policy. Environmental Science and Technology, 47(18), 10108-10110. https://doi.org/10.1021/es403443n

Löwe, R., Urich, C., Sto. Domingo, N., Mark, O., Deletic, A., \& Arnbjerg-Nielsen, K. (2017). Assessment of urban pluvial flood risk and efficiency of adaptation options through simulations - A new generation of urban planning tools. Journal of Hydrology, 550, 355-367. https://doi.org/10.1016/j.jhydrol.2017.05.009

Magliocca, N., \& Walls, M. (2018). The role of subjective risk perceptions in shaping coastal development dynamics. Computers, Environment and Urban Systems, 71, 1-13. https://doi.org/10.1016/j.compenvurbsys.2018.03.009

Martin-Breen, P., and J. M. Anderies. 2011. Resilience: A Literature Review. Brighton: Bellagio Initiative. http://opendocs.ids.ac.uk/opendocs/handle/123456789/3692

McClymont, K., Morrison, D., Beevers, L., \& Carmen, E. (2019). Flood resilience: a systematic review. In Journal of Environmental Planning and Management, 63(7), 1151-1176. Routledge. https://doi.org/10.1080/09640568.2019.1641474

McNamara, D. E., \& Keeler, A. (2013). A coupled physical and economic model of the response of coastal real estate to climate risk. Nature Climate Change, 3(6), 559-562. https://doi.org/10.1038/nclimate1826

McNamara, D. E., \& Werner, B. T. (2008). Coupled barrier island-resort model: 1. Emergent instabilities induced by strong human-landscape interactions. Journal of Geophysical Research: Earth Surface, 113(1), 1-10. https://doi.org/10.1029/2007JF000840

Mendelsohn, R. (2000). Efficient adaptation to climate change. Climatic Change, 45(3-4), 583-600. https://doi.org/10.1023/A:1005507810350

Michaelis, T., Brandimarte, L., \& Mazzoleni, M. (2020). Capturing flood-risk dynamics with a coupled agent-based and hydraulic modelling framework. Hydrological Sciences Journal, 1-16. https://doi.org/10.1080/02626667.2020.1750617

Mochizuki, J., Keating, A., Liu, W., Hochrainer-Stigler, S., \& Mechler, R. (2018). An overdue alignment of risk and resilience? A conceptual contribution to community resilience. Disasters, 42(2), 361-391. https://doi.org/10.1111/disa.12239

Mustafa, A., Bruwier, M., Archambeau, P., Erpicum, S., Pirotton, M., Dewals, B., \& Teller, J. (2018). Effects of spatial planning on future flood risks in urban environments. Journal of Environmental Management, 225(February), 193-204. https://doi.org/10.1016/j.jenvman.2018.07.090

Noll, B., Filatova, T., \& Need, A. (2020). How does private adaptation motivation to climate change vary across cultures? Evidence from a meta-analysis. In International Journal of Disaster Risk Reduction 46, 101615. Elsevier Ltd. https://doi.org/10.1016/j.ijdrr.2020.101615

O'Sullivan, D., Evans, T., Manson, S., Metcalf, S., Ligmann-Zielinska, A., \& Bone, C. (2016). Strategic directions for agent-based modeling: avoiding the YAAWN syndrome. Journal of Land Use Science, 11(2), 177-187. https://doi.org/10.1080/1747423X.2015.1030463

Intergovernmental Panel on Climate Change. (2014). Summary for Policymakers. In Climate Change 2013 - The Physical Science Basis: Working Group I Contribution to the Fifth Assessment Report of the Intergovernmental Panel on Climate Change (pp. 1-30). Cambridge: Cambridge University Press. doi:10.1017/CBO9781107415324.004Rodríguez, H., Donner, W., \& Trainor, J. E. (Eds.). (2018). Handbook of Disaster Research. Springer International Publishing. https://doi.org/10.1007/978-3-319-63254-4

Rogers, R. W. (1975). A Protection Motivation Theory of Fear Appeals and Attitude Change. The Journal of Psychology, 91(1), 93-114. https://doi.org/10.1080/00223980.1975.9915803

Schill, C., Anderies, J. M., Lindahl, T., Folke, C., Polasky, S., Cárdenas, J. C., Crépin, A. S., Janssen, M. A., Norberg, J., \& Schlüter, M. (2019). A more dynamic understanding of human behaviour for the Anthropocene. Nature Sustainability, 2(12), 1075-1082. https://doi.org/10.1038/s41893-019-0419-7 
Schlüter, M., Baeza, A., Dressler, G., Frank, K., Groeneveld, J., Jager, W., Janssen, M. A., McAllister, R. R. J., Müller, B., Orach, K., Schwarz, N., \& Wijermans, N. (2017). A framework for mapping and comparing behavioural theories in models of social-ecological systems. Ecological Economics, 131, 21-35. https://doi.org/10.1016/j.ecolecon.2016.08.008

Sivapalan, M., Savenije, H. H. G., \& Blöschl, G. (2012). Socio-hydrology: A new science of people and water. Hydrological Processes, 26(8), 1270-1276. https://doi.org/10.1002/hyp.8426

Smajgl, A., Brown, D. G., Valbuena, D., \& Huigen, M. G. A. (2011). Empirical characterisation of agent behaviours in socioecological systems. Environmental Modelling and Software, 26(7), 837-844. https://doi.org/10.1016/j.envsoft.2011.02.011

Sobiech, C. (2013). Regional Research Framework. In Agent-Based Simulation of Vulnerability Dynamics (pp. 75-91). Springer, Berlin, Heidelberg.Steg, L., \& Vlek, C. (2009). Encouraging pro-environmental behaviour: An integrative review and research agenda. Journal of Environmental Psychology, 29(3), 309-317. https://doi.org/10.1016/j.jenvp.2008.10.004

Stern, N. (2016). Economics: Current climate models are grossly misleading. Nature, 530(7591), 407-409. https://doi.org/10.1038/530407a

Tempels, B., \& Hartmann, T. (2014). A co-evolving frontier between land and water: dilemmas of flexibility versus robustness in flood risk management. Water International, 39(6), 872-883. https://doi.org/10.1080/02508060.2014.958797

Tonn, G., \& Guikema, S. (2018). An Agent-Based Model of Evolving Community Flood Risk. Risk Analysis, 38(6), 1258-1278. https://doi.org/10.1111/risa.12939

Tonn, G., Guikema, S., \& Zaitchik, B. (2019). Simulating Behavioral Influences on Community Flood Risk under Future Climate Scenarios. Risk Analysis, 40(4), 884-898. https://doi.org/10.1111/risa.13428

Walls, M., Magliocca, N., \& McConnell, V. (2018). Modeling coastal land and housing markets: Understanding the competing influences of amenities and storm risks. Ocean and Coastal Management, 157, 95-110. https://doi.org/10.1016/j.ocecoaman.2018.01.021

Walsh, B., \& Hallegatte, S. (2019). Measuring Natural Risks in the Philippines: Socioeconomic Resilience and Wellbeing Losses. World Bank Policy Research Working Paper, 8723. https://ssrn.com/abstract=3326958.

Werner, B. T., \& McNamara, D. E. (2007). Dynamics of coupled human-landscape systems. Geomorphology, 91(3-4), 393407. https://doi.org/10.1016/j.geomorph.2007.04.020

Wilson, R. S., Herziger, A., Hamilton, M., \& Brooks, J. S. (2020). From incremental to transformative adaptation in individual responses to climate-exacerbated hazards. Nature Climate Change, 10(3), 200-208. https://doi.org/10.1038/s41558020-0691-6 